\title{
Characterization of In Vivo Expression of the Human Papillomavirus Type 16 E4 Protein in Cervical Biopsy Tissues
}

\author{
Joel M. Palefsky, „*\$ Barbara Winkler," Jorg-Peter Rabanus," Christine Clark," \\ Shew Chan," Victor Nizet," and Gary K. Schoolnik* \\ *Departments of Medicine and Microbiology and Immunology, the Divisions of Geographic Medicine and Infectious Diseases, and the \\ Howard Hughes Medical Institute, Stanford University, Stanford, California 94305; the Departments of ${ }^{\ddagger}$ Laboratory Medicine and \\ ${ }^{8}$ Stomatology, University of California, San Francisco, California 94143; the "Department of Pathology, Columbia University \\ College of Physicians and Surgeons, New York, 10032; and 'Life Technologies, Inc., Gaithersburg, Maryland 20877
}

\begin{abstract}
The role of human papillomavirus (HPV) proteins in the pathogenesis of cervical intra-epithelial neoplasia (CIN) and invasive cervical cancer is poorly understood. To characterize E4 protein expression in 49 paraffin-embedded cervical biopsies representing different histopathologic grades of disease, antibodies were elicited to a synthetic peptide corresponding to amino acids 20-34 of a protein predicted to be encoded by the HPV 16 E4 open reading frame. The $\mathbf{E} 4$ protein was detected throughout the spectrum of CIN, from CIN 1 to CIN 3. Expression was localized to the cell nucleus, primarily in the superficial layers of the squamous cervical epithelium. Ultrastructural studies showed that the E4 protein was organized into compact, intranuclear arrays $25-35 \mathrm{~nm}$ in diameter. E4 protein expression was also demonstrated in some histologically normal tissues containing HPV 16 DNA, but not in any of five cervical cancers containing HPV 16 DNA. These results suggest that E4 protein expression may precede development of light microscopic tissue abnormalities, that it may continue through the spectrum of CIN, and that expression of this protein may be reduced or terminated in invasive cancer. The function of this protein remains unknown, but its nuclear localization may be consistent with a role in viral maturation. (J. Clin. Invest. 1991.87:21322141.) Key words: human papillomavirus • cervical intra-epithelial neoplasia $\bullet$ cervical cancer $\cdot \mathbf{E} 4$ protein
\end{abstract}

\section{Introduction}

The relationship between human papillomavirus (HPV) ${ }^{1}$ infection and disease of the human uterine cervix, ranging from cervical intra-epithelial neoplasia (CIN) to squamous cell carcinoma (SCC) is now well established (1-3). Several studies have suggested that CIN may progress from low grade disease (CIN 1) to high grade disease (CIN 3) over a period of months to years, and that CIN 3 is associated with a high risk of progres-

Address correspondence to Dr. Palefsky, Department of Laboratory Medicine, Box 0100, University of California, San Francisco, CA 94143-0100.

Received for publication 15 August 1990 and in revised form 22 January 1991

1. Abbreviations used in this paper: CIN, cervical intra-epithelial neoplasia; HPV, human papillomavirus; SCC, squamous cell carcinoma.

J. Clin. Invest.

(c) The American Society for Clinical Investigation, Inc.

$0021-9738 / 91 / 06 / 2132 / 10 \$ 2.00$

Volume 87, June 1991, 2132-2141 sion to invasive cervical cancer $(4,5)$. HPV types 6 and 11 have been detected primarily in association with low grade cervical disease (condyloma acuminatum and CIN 1), whereas types $16,18,31,33$, and 35 have been detected in association with high grade cervical disease and a higher risk of progression to malignancy (6-11). Of the latter group, HPV 16 has been the most frequently detected HPV type in several studies of women with CIN or cervical cancer (12).

The genome of HPV 16 consists of the early region (E) and the late region (L) (13). The latter can encode the $\mathrm{L} 1$ and $\mathrm{L} 2$ proteins which are thought to be the major and minor capsid proteins, respectively; these are believed to be expressed only in productive viral infection (14). The E region proteins E1 and E2 are important in viral transcriptional regulation (15-17), whereas the E6 and E7 proteins are thought to be more directly involved in malignant transformation, with the latter playing the major role (18-20). In contrast, the function of the proteins encoded by the E4 open reading frame (ORF) is unknown. In plantar warts containing HPV 1a DNA, the E4 proteins appear to constitute a family of polypeptides ranging in size from 10 to $17 \mathrm{kD}$. They are of considerable interest because they are expressed in great abundance, comprising up to one-third of the total cellular mass (21). Similarly, mRNA species encoded by the E4 ORF are among the most abundant viral transcripts in biopsies of CIN and condyloma $(22,23)$.

At this time, little is known about the functional role of early region proteins during the progression of HPV-infected lesions from infection of histologically normal tissue to the development of CIN and SCC. As a first approach to this fundamental question, we sought to characterize the expression of early region proteins at each stage of $\mathrm{CIN}$ and in invasive cancer. In this report, we describe the preparation of antibodies specific for the E4 protein of HPV 16, and their use in the characterization of E4 protein expression in HPV 16-infected cervical tissues ranging from histologically normal to invasive cancer.

\section{Methods}

Collection of clinical specimens. After a routine Papanicolaou smear was performed, a Dacron ${ }^{\mathrm{TM}}$ cervical swab was used to obtain exocervical and endocervical material from 49 consenting women attending four San Francisco Bay area colposcopy clinics; each woman was referred to one of these clinics because of a recent history of an abnormal Papanicolaou smear. Swabs were placed in a 1-ml solution consisting of $25 \mathrm{mM}$ Tris $\mathrm{HCl}$ buffer, $\mathrm{pH} 8.0$, containing $4.2 \mathrm{M}$ guanidium isothiocyanate (Sigma Chemical Co., St. Louis, MO), 0.5M 2-ME (Sigma Chemical Co.), and $0.5 \%$ (wt/vol) $N$-lauroylsarcosine (Sigma Chemical Co.), and stored at $-20 \mathrm{C}$. A biopsy of a region fulfilling colposcopic criteria (24) for cervical disease was obtained during the same visit from each subject. Cervical biopsies were fixed in formalin, embedded in paraffin, and cut into $4-\mu \mathrm{m}$ tissue sections; these sections were prepared 
for routine histopathologic examination and for immunohistochemical studies using the antibodies specific for the E4 protein described below. Histopathology was evaluated using standard diagnostic criteria for the female genital tract (24).

Preparation of the HPV 16 and HPV 6 E4 synthetic peptides. A peptide corresponding to amino acids 20-34 (Gly-Ser-Thr-Trp-ProThr-Thr-Pro-Pro-Arg-Pro-Ile-Pro-Lys-Pro) of the E4 ORF of HPV 16 (HPV 16 E4[20-34]) was synthesized by solid-phase techniques using commercially available amino acids and tert-butoxy carbonyl-protecting groups (Peninsula Laboratories, Belmont, CA) (25). A peptide sequence found in both HPV 6 and 11, corresponding to amino acids 33-46 (Asn-Leu-Leu-His-Thr-Pro-Pro-His-Arg-Pro-Pro-Pro-Leu-Cys) of the E4 ORF of HPV 6 was also synthesized. As indicated in Fig. 1, both sequences are derived from the homologous regions of their respective E4 ORFs. After synthesis, the amino acid compositions and sequences of the peptides were confirmed by amino acid analysis and automated Edman degradation, respectively. For the purpose of covalent coupling of the HPV 16 E4[20-34] peptide to thyroglobulin, a cysteine residue was added to the peptide's carboxyl terminus during synthesis; conjugation of the peptide to thyroglobulin was then performed using the heterobifunctional cross-linker $m$-maleimidobenzoyl- $n$-hydroxysuccinimide ester (MBS) (Pierce Chemical Co., Rockford, IL) (26).

A synthetic peptide corresponding to the entire predicted HPV 16 E4 ORF was synthesized as well. The HPV 16 E4 ORF does not encode an $\mathrm{NH}_{2}$-terminal methionine, and the predicted sequence of the native protein includes a splice from the E1 ORF to amino acid 10 of the E4 ORF (27). This sequence was therefore prepared synthetically using a peptide synthesizer (No. 9050; Milligen, Inc., Cambridge, MA) and $\mathrm{N}$ - $\alpha$-fluorenylmethoxylcarbonyl (Fmoc)-protected amino acids activated as pentafluorophenyl esters (28). Protected amino acids and resins (substituted at $0.9 \mathrm{mEq} / \mathrm{g}$ ) used for synthesis were purchased from Milligen, Inc. Synthesis was accomplished using successive cycles of deprotection with $20 \% \mathrm{wt} / \mathrm{vol}$ piperidine and coupling in the presence of 1-hydroxybenzotriazole (Aldridge Chemical Co., Milwaukee, WI) as described (28). Peptides were cleaved from $2 \mathrm{~g}$ of resin by acidolysis using $30 \mathrm{ml}$ of a solution containing $95 \%$ trifluoroacetic acid (Aldridge Chemical Co.), 5\% distilled water, and $1 \mathrm{mg}$ of phenol for a period of 8 $h$. The solution was separated from the resin, evaporated, and extracted with $200 \mathrm{ml}$ of cold ether. The precipitated peptide was dried, resuspended in $100 \mathrm{ml}$ of $5 \%$ acetic acid, lyophilized, and characterized by amino acid analysis and $\mathrm{NH}_{2}$-terminal sequencing.

Preparation of affinity-purified HPV 16 E4 peptide-specific antisera. To elicit antibodies to synthetic peptide HPV 16 E4[20-34], the peptide-thyroglobulin conjugate was emulsified with CFA and injected into New Zealand White rabbits; 6 wk later, the conjugate was administered with IFA, and the animals were bled $10 \mathrm{~d}$ thereafter. The IgG fraction was precipitated from the corresponding pre-immune sera and from the hyperimmune $\mathrm{E} 4$ antisera with $2 \mathrm{M}$ ammonium sulfate, followed by anion-exchange chromatography with DEAE-cellulose (Sigma Chemical Co.). For the purpose of affinity purification, the synthetic peptide was conjugated to BSA with the heterobifunctional cross-linker succinimidyl 4-( $n$-maleimidomethyl) cyclohexane-1-carboxylate (SMCC) (Pierce Chemical Co.), and the peptide-BSA conjugate linked to an Affigel 15 column (Bio-Rad Laboratories, Richmond, CA). Bound (E4 peptide-specific) IgG was eluted in $20 \mathrm{mM}$ glycine buffer, $\mathrm{pH} 2.5$, and neutralized with $30 \mathrm{mM}$ Tris $\mathrm{HCl}$ buffer, $\mathrm{pH}$ 8.0. The E4 peptide-specific IgG, the pre-immune IgG, and the IgG fraction of the same immune sera that did not bind the column were assessed for reactivity to the HPV 16 E4[20-34] peptide by a solid-phase RIA.

Radioimmunoassays. Polystyrene microtiter plate wells were incubated overnight with $5 \mu \mathrm{g}$ of HPV 16 E4[20-34]-SMCC-BSA conjugate or HPV 6[33-46]-SMCC-BSA conjugate in $0.1 \mathrm{M}$ sodium carbonate, pH 9.2, at room temperature. Wells were then washed with blocking buffer $(0.1 \%$ BSA in PBS). The affinity-purified antibodies to HPV 16 [20-34], at an initial concentration of $1.4 \mu \mathrm{g} / \mathrm{ml}$, were then added in serial 1:2 dilutions in blocking buffer containing 0.17\% BRIJ 35 (Pierce Chemical Co.), beginning with a dilution of the initial antibody preparation of 1:50. Each dilution was tested in duplicate. The plates were incubated at $37^{\circ} \mathrm{C}$ for $3 \mathrm{~h}$ and the wells were then washed with BRIJblocking buffer. $5 \times 10^{4} \mathrm{cpm}$ of ${ }^{125} \mathrm{I}$-protein $\mathrm{A}$ were added in BRIJblocking buffer to each well and the plate was incubated for $3 \mathrm{~h}$ at $37^{\circ} \mathrm{C}$. Finally, the wells were washed with BRIJ-blocking buffer, cut out of the plate, and the bound radioactivity was quantitated by gamma counting. The results for each dilution are given as the average of the duplicate wells.

In a separate experiment, polystyrene microtiter wells were incubated overnight with $5 \mu \mathrm{g} / \mathrm{ml}$ of HPV $16 \mathrm{E} 4[20-34]$ or with $30 \mu \mathrm{g} / \mathrm{ml}$ of the full-length synthetic HPV 16 E4 peptide. Greater concentrations were chosen for the latter to obtain approximately equimolar concentrations of the E4[20-34] epitope, since the molecular mass of the fulllength peptide is approximately six times greater than the E4[20-34] peptide. Affinity-purified antibodies to HPV 16[20-34], at an initial concentration of $1.65 \mu \mathrm{g} / \mathrm{ml}$, were then added in serial $1: 2$ dilutions in the Brij blocking buffer, beginning with a dilution of 1:50. Each dilution was tested in triplicate. The plates were incubated at $37^{\circ} \mathrm{C}$ for $3 \mathrm{~h}$ and the wells were then washed with BRIJ-blocking buffer. $7 \times 10^{4} \mathrm{cpm}$ of ${ }^{125}$ I-protein A were added in BRIJ-blocking buffer to each well, the plate was incubated for $3 \mathrm{~h}$ at $37^{\circ} \mathrm{C}$, and the RIAs were performed as described above.

Reactivity of the antibodies to HPV 16 E4[20-34] to the full-length synthetic $E 4$ protein sequence. Reactivity of the antibodies elicited to HPV 16[20-34] for the full-length protein described above was studied by RIA (as described above), and by Western blot analysis. $2 \mu \mathrm{g}$ of the

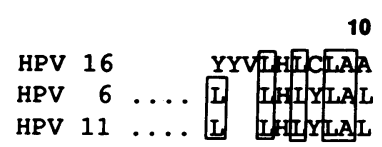

50

HPV 16

HPV 6

HPV 11

KHRRISSDQD

KTQCKRRIGNEHE

KTACRRRIGSEHV

HPV 16

HPV 6

TVLOSSLHLT

HPV 11
HPV16 E4[20-34]
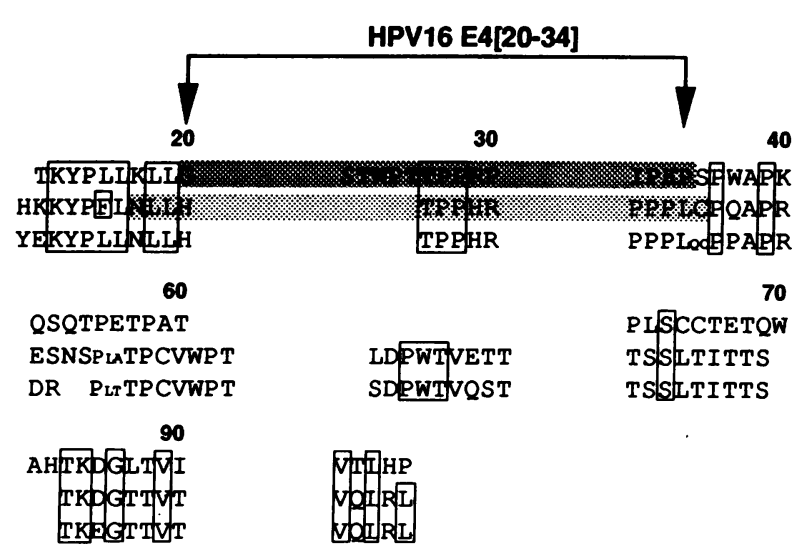

Figure 1. Amino acid sequence of synthetic peptide HPV $16 \mathrm{E} 4[20$ 34]. The amino acid sequences specified by the HPV 16,6 , and 11 ORFs were derived from the corresponding genomic sequences (13, $53,54)$, aligned to depict regions of homology and numbered according to the HPV 16 sequence. The predicted $\mathrm{NH}_{2}$-terminal sequences of these ORFs are not shown. Identical amino acids are enclosed in the boxes. The HPV 16 E4[20-34] sequence is denoted in boldface; antibodies to this sequence were used in this study to detect the E4 protein in cervical tissues containing HPV 16 DNA. The one-letter amino acid code is used. 
synthetic full-length E4 protein were subjected to SDS-PAGE using $18 \%$ polyacrylamide in the resolving gel (29), and the protein was transferred to a nitrocellulose membrane (30). The membrane was incubated in $10 \mathrm{ng} / \mathrm{ml}$ of affinity-purified antibodies to HPV $16 \mathrm{E} 4[20-34]$ for $1.5 \mathrm{~h}$ at $37^{\circ} \mathrm{C}$, followed by incubation in $15,000 \mathrm{cpm} / \mathrm{ml}$ of ${ }^{125} \mathrm{I}$-protein $\mathrm{A}$ for $1.5 \mathrm{~h}$ at room temperature. The membrane was washed and exposed to Kodak XAR 5 film overnight at $-70^{\circ} \mathrm{C}$.

Immunohistochemistry. Formalin-fixed, paraffin-embedded cervical biopsies were cut into sections $4 \mu \mathrm{m}$ in thickness, placed on glass slides coated with aminopropyltriethoxysilane (AES) (Sigma Chemical Co.), and baked overnight at $60^{\circ} \mathrm{C}$. Each tissue was assessed with preimmune IgG and affinity-purified IgG at a concentration of $1.4 \mu \mathrm{g} / \mathrm{ml}$. Tissues were also assessed with immune IgG from which the peptidespecific antibodies had been removed by affinity chromatography; these antibodies, which did not bind the peptide, were also used at a concentration of $1.4 \mu \mathrm{g} / \mathrm{ml}$. Immunohistochemistry was performed according to the method of Hsu and Raine (31). Slides were deparaffinized in xylene, followed by graded ethanol washes from $100 \%$ ethanol to $70 \%$ ethanol. Slides were washed in $\mathbf{0 . 2 \%}$ Tween (Sigma Chemical Co.) in PBS, followed by two washes in PBS. $10 \%$ normal goat serum in PBS was added to the slides for $30 \mathrm{~min}$ at room temperature in a humidity chamber. The slides were incubated with the IgG preparations described above in PBS with $0.05 \%$ Tween for $16 \mathrm{~h}$ at $4^{\circ} \mathrm{C}$ or for 1 $\mathrm{h}$ at room temperature, and were washed in PBS with $0.2 \%$ Tween. Biotinylated goat anti-rabbit IgG in PBS with $0.05 \%$ Tween was added for $30 \mathrm{~min}$ (ABC; Vector Laboratories, Inc., Burlingame, CA). Avidinalkaline phosphatase conjugate in PBS with $0.05 \%$ Tween was added to the slides for $1 \mathrm{~h}$ at room temperature, followed by incubation with Red alkaline phosphatase substrate (Vector Laboratories, Inc.) for $1 \mathrm{~h}$ at room temperature in the dark. The slides were washed in distilled water, counterstained lightly with hematoxylin, dehydrated through graded washes from $70 \%$ to $100 \%$ ethanol, and mounted with Permount.

To be considered positive for the $\mathrm{E} 4$ protein, each tissue was required to satisfy the following criteria for antibody specificity: (a) affinity-purified antibodies to E4[20-34]-bound epithelial, but not stromal structures; $(b)$ the IgG fraction of the pre-immune sera did not bind epithelial structures when used in the same concentration as the affinity-purified antibodies; and (c) immune IgG from which the E4-specific antibodies had been removed by affinity chromatography did not bind epithelial structures when used in the same concentration as the affinity-purified antibodies. The latter criterion was used in place of competitive inhibition experiments with the soluble synthetic peptide because the peptide precipitated onto the surface of the slide during this assay.

Immunoelectronmicroscopy. Immunoelectron microscopy was performed on a biopsy of a cervical lesion obtained at the time of cervical conization using previously described techniques $(32,33)$. Subsequent histopathologic assessment of tissue adjacent to the area of the biopsy demonstrated CIN 2 . The biopsy specimen was immediately fixed in $4 \%$ paraformaldehyde in double-distilled water at $4^{\circ} \mathrm{C}$ for $2 \mathrm{~h}$. The specimen was cut into blocks measuring $1 \mathrm{~mm} \times 1 \mathrm{~mm} \times t \mathrm{~mm}$, (where $t$ equals the thickness of the epithelium), infiltrated successively in $4 \%$ paraformaldehyde with $10,20,40$, and $78 \%$ sucrose in PBS, pH 7.2 , and shock-frozen in slush nitrogen $\left(-210^{\circ} \mathrm{C}\right)$. Ultrathin frozen sections were obtained on dry glass knives in an Ultracut FC-4E unit at $-120^{\circ} \mathrm{C}$ (Reichert AG, Vienna, Austria). Sections were collected with droplets of $4 \%$ paraformaldehyde in $2.3 \mathrm{M}$ sucrose in PBS and placed after thawing onto carbon-reinforced Pioloform $F$ hexagonal gold grids (Wacker Chemie, Munich, FRG). Nonspecific binding sites were blocked with $0.1 \%$ gelatin and $0.5 \%$ BSA in PBS, and subsequently with goat nonimmune serum. The sections were then incubated for $1 \mathrm{~h}$ in $700 \mathrm{ng} / \mathrm{ml}$ antibodies to HPV $16 \mathrm{E} 4[20-34]$ in PBS containing $0.1 \%$ gelatin. Sections were then incubated with affinity-purified goat antirabbit IgG conjugated with 5-nm colloidal gold particles (Janssen, Beerse, Belgium). As a control, sections were also incubated in equal concentrations of rabbit pre-immune IgG. After staining with uranyl acetate, the specimens were stabilized with $1.0 \%$ methylcellulose
(Methocyl; Fluka Feinchemikalien, Neu-Ulm, FRG), and examined at $80 \mathrm{kV}$ with a Jeol JEM-1200 EX electron microscope.

Detection of HPV DNA. The HPV type present in the cervix was determined by Southern blot hybridization of cervical swab material obtained before cervical biopsy. The guanidium isothiocyanate collection medium containing exfoliated cervical cells was extracted with phenol/chloroform, followed by isopropanol precipitation to partially purify the DNA. DNA was digested with $10 \mathrm{U}$ Pst I for $2 \mathrm{~h}$ at $37^{\circ} \mathrm{C}$ in 20 $\mu \mathrm{l}$, and the fragments were electrophoresed in a $1 \%$ agarose gel. Southern blot hybridization (34) was performed with probes consisting of ${ }^{32}$ P-labeled nick-translated genomic DNA of HPV types 16,18 , and 31 separately, and a mixture of probes corresponding to HPV 6 and 11 . Initial washes were performed under conditions of temperature midpoint $-25^{\circ} \mathrm{C}$. After appropriate exposure to Kodak XAR-5 film at $-70^{\circ} \mathrm{C}$, the blots were rewashed under conditions of temperature midpoint $-10^{\circ} \mathrm{C}$ and re-exposed.

Polymerase chain reaction studies for the detection of HPV DNA were performed on 10 histologically normal tissue blocks using a modification of the method of Shibata et al. (35). Oligonucleotide primers (Operon Inc., Richmond, CA) were selected to amplify a portion of the E6 region specific to each of HPV 16, 18, and 31, as well as a portion common to HPV 6 and 11.

Sequential $7-\mu \mathrm{m}$ tissue sections were cut from each block and placed in separate Eppendorf tubes. Before amplification, tissue sections from each block were deparaffinized in xylene and washed in 95\% ethanol. Polymerase chain reaction studies were performed after digestion of the section with $100 \mu \mathrm{g} / \mathrm{ml}$ Proteinase K (Sigma Chemical Co.). The Proteinase $\mathrm{K}$ was then inactivated by boiling for $10 \mathrm{~min}$. One-half of the digested material was brought to a final volume of $100 \mu \mathrm{l}$ in $10 \mathrm{mM}$ Tris-HCl buffer, $\mathrm{pH} 8.3$, containing a concentration of $1 \mu \mathrm{M}$ of primers for amplification of hemoglobin, HPV 16, and HPV 18, 50 $\mathrm{mM} \mathrm{KCl}, 2.5 \mathrm{mM} \mathrm{MgCl}, 200 \mu \mathrm{g} / \mathrm{ml}$ gelatin, $200 \mu \mathrm{M}$ dNTPs, and $5 \mathrm{U}$ Taq polymerase (Perkin-Elmer Cetus Corp., Norwalk, CT). The remaining one-half of the digested material was added to a similar solution containing primers for amplification of HPV 6/11 and HPV 31 instead of HPV types 16 and 18. 50 cycles of amplification were performed in a Thermal Cycler (Perkin-Elmer Corp.).

Oligonucleotide probes specific for each of HPV 16, 18, 31, and 6/11 DNA were synthesized (Operon, Inc.) and were end-labeled with ${ }^{32} \mathrm{P}$, and the specificity of the primers and probe for each HPV DNA type was confirmed by dot-blot and Southern blot analysis in cross-hybridization experiments. One-fifth of each of the tissue amplification mixtures was probed separately for each of the potential target DNA sequences in a dot blot format, and the size of the amplification product was confirmed in selected samples by Southern blot analysis. Membranes were exposed to Kodak XAR-5 film at $-70^{\circ} \mathrm{C}$; clearly detectable signal was usually seen within 1-2 h of exposure.

Positive controls for the presence of tissue and the integrity of the reaction consisted of the amplification of human alpha hemoglobin DNA from each tissue. As a positive control for HPV DNA amplification, cloned DNA corresponding to each of the HPV types was amplified as well. Three types of negative controls were used: $(a)$ to minimize the possibility of false-positives due to contamination from one specimen to another in the laboratory, each mixture with all components of the reaction except the target DNA was amplified; $(b)$ reaction mixtures containing the cloned HPV DNA of each type were amplified with each primer set to rule out cross-reactivity, and $(c)$ histologically normal cervical tissues from women whose cervical swabs were HPVnegative, and whose tissues were negative for the $\mathrm{E} 4$ protein by immunohistochemistry, were studied to minimize the possibility of contamination due to tissue processing and/or nonspecificity of the amplification signal.

HPV DNA in situ hybridization. HPV DNA in situ hybridization was performed on selected tissue sections using the ViraType ${ }^{\mathbb{R}}$ In-Situ tissue hybridization technique (Life Technologies, Inc., Gaithersburg, MD). Three sequential tissue sections from each biopsy, adjacent to those used for polymerase chain reaction studies, were probed for HPV 
6 and 11, HPV 16 and 18, and HPV 31,33, and 35, respectively, according to the conditions recommended by the manufacturer.

\section{Results}

Identification of an E4 synthetic peptide sequence yielding HPV 16-specific antibodies. The predicted amino acid sequences encoded by the E4 ORFs of HPVs 16, 6, and 11 were compared (Fig. 1) in order to identify a region of the E4 protein that might contain an HPV 16-specific epitope. A peptide corresponding to amino acids 20 to 34 of the E4 ORF of HPV 16 (termed HPV 16 E4[20-34]) was selected for synthesis because it contains amino acids unique to the HPV 16 sequence, and therefore was predicted to elicit antibodies specific for the E4 protein of HPV 16. In addition, this sequence corresponds to a hydrophilic region of the protein $(36,37)$, contains a probable betareverse turn (38), and thus was expected to elicit antibodies that would bind the full-length E4 protein in HPV-infected tissues.

Specificity of antibodies to the HPV 16 E4 [20-34] peptide. Monospecific IgG antibodies to the HPV 16 E4 [20-34] peptide were obtained from hyperimmune sera by affinity purification and characterized using a solid-phase RIA. As a measure of the specificity of these antibodies, their reactivity to the immunizing peptide was compared with a peptide corresponding to the same region of the HPV 6 and 11 E4 ORF (Fig. $2 a$ ). The affinity-purified IgG exhibited reactivity for the HPV $16 \mathrm{immu}$ nizing peptide in concentrations as low as $280 \mathrm{pg} / \mathrm{ml}$, representing a dilution of the initial antibody preparation of $\sim 1: 5,000$. In contrast, these antibodies did not recognize the HPV 6 and 11 E4 peptide, indicating that they were specific for the HPV 16 E4 sequence. In addition, a control antibody preparation consisting of an equal concentration of IgG antibodies prepared from the pre-immune serum did not exhibit any reactivity to the HPV 16 E4 peptide. Similarly, IgG from the non-pep- tide binding fraction of the immune serum did not exhibit reactivity (data not shown), providing further evidence for the specificity of the affinity-purified antibodies.

To determine if the antibodies to HPV 16 E4[20-34] could recognize the full-length HPV $16 \mathrm{E} 4$ protein, a 98 amino acid polypeptide corresponding to the entire predicted E1-E4 spliced gene product was synthesized as described above. Antibodies to the HPV 16 E4 [20-34] peptide bound the full-length polypeptide when tested either by Western blotting (data not shown) or solid-phase RIA (Fig. $2 b$ ), indicating that the epitope specified by amino acids $20-34$ of the HPV 16 E4 ORF is antigenic within the context of the predicted full-length $E 4$ protein. However, the reactivity of the antibodies to HPV 16 E4[20-34] was approximately four times greater for the small immunizing peptide than for the full-length protein. In the experiment depicted in Fig. 2b, the affinity-purified IgG reacted with the small immunizing peptide at concentrations as low as $5.50 \mathrm{pg} / \mathrm{ml}$, representing a dilution of the initial antibody preparation of $\sim 1: 3,000$. In contrast, these antibodies reacted with the full-length $\mathrm{E} 4$ protein at concentrations as low as $2.4 \mathrm{ng} / \mathrm{ml}$, which corresponded to a dilution of about 1:700.

Expression of the E4 protein in CIN and cervical carcinoma tissues. Immunohistochemical studies of 49 cervical tissues with antibodies to HPV 16 E4 [20-34] were performed in order to answer the following questions: Is the E4 protein expressed in HPV 16-infected, histologically abnormal tissues? If so, what is the location of the $\mathrm{E} 4$ protein within the cell? How does expression vary with the stage of cervical disease? In which cell layers of the squamous epithelium is the E4 protein expressed and is its expression linked to cellular differentiation? The results of these studies are presented in Table I and Fig. 3.

12 tissues with histologic abnormalities ranging from CIN 1 to CIN 3 were obtained from subjects whose corresponding cervical swabs contained HPV 16 DNA (Table I). Expression
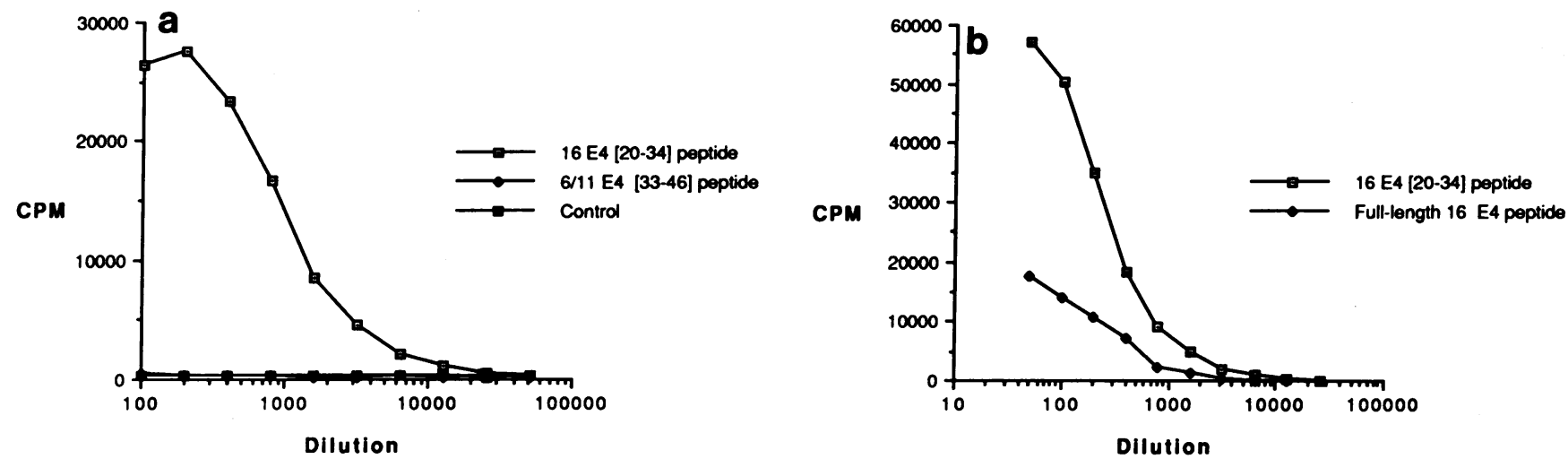

Figure 2. (a) The specificity of antibodies to HPV 16 E4[20-34]. An antiserum to HPV 16 E4[20-34] was prepared and the mono-specific IgG antibodies were obtained by affinity chromatography. The antigenic specificity of these antibodies was determined by RIA using the homologous HPV 16 E4[20-34] peptide as an antigen versus a heterologous peptide derived from the same region of the HPV 6 E4 ORF. The amino acid sequence of the HPV 16 E4[20-34] peptide is $\mathrm{H}_{2} \mathrm{~N}$-GSTWPTTPPRPIPKP-COOH, whereas the sequence of the corresponding HPV 6 E4[33-46] peptide is $\mathrm{H}_{2} \mathrm{~N}-\mathrm{NLLHTPPHRPPPLC}-\mathrm{COOH}$. The underlined residues in each sequence are identical. The affinity-purified antibodies bound only the HPV 16 E4[20-34] sequence. The control indicated in this figure consists of wells not coated with any antigen, and represents background reactivity. In addition, the non-peptide binding fraction of the immune serum did not demonstrate any reactivity (data not shown). (b) The crossreactivity of affinity-purified antibodies to the HPV16 E4[20-34] peptide for the full-length E4 protein. Affinity-purified antibodies were prepared as described above, and their reactivities for this peptide versus the full-length 98 amino acid E4 protein were then compared using a solid-phase RIA. Specific binding to the full-length E4 protein was noted at antibody concentrations as low as $2.4 \mathrm{ng} / \mathrm{ml}$ (which corresponded to a dilution of this antibody preparation of $\sim 1: 700$ ). The same antibodies bound the small immunizing peptide approximately four times better, reacting with it at concentrations as low as $550 \mathrm{pg} / \mathrm{ml}$ (which corresponded to a dilution of this antibody preparation of $\sim 1: 3,000$ ). 

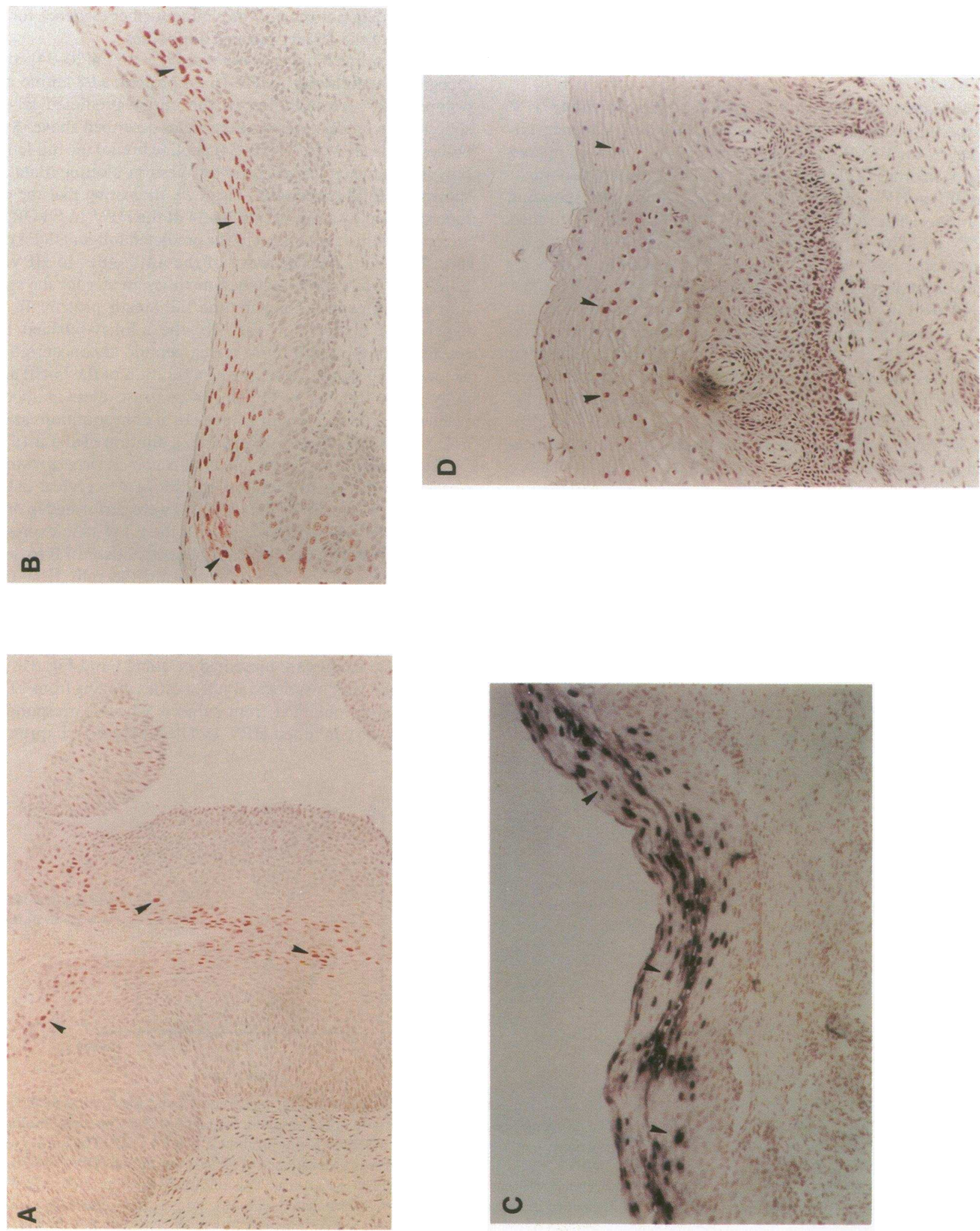
Table I. Expression of the E4 Protein in Cervical Biopsies

\begin{tabular}{lccc}
\hline & \multicolumn{3}{c}{ HPV DNA Type by Southern Blot Hybridization } \\
\cline { 2 - 4 } & HPV & HPV & $\begin{array}{c}\text { HPV } \\
\text { Hegative* }\end{array}$ \\
\hline Histopathology & 16 & $6 / 11$ & $0 / 10$ \\
Normal & $1 / 2$ & $0 / 1$ & $0 / 5$ \\
CIN 1 & $4 / 4$ & $0 / 1$ & $0 / 3$ \\
CIN 2 & $2 / 2$ & - & $0 / 2$ \\
CIN 3 & $6 / 6$ & - & - \\
Condyloma & - & $0 / 4$ & $0 / 4$ \\
SCC & $0 / 5$ & - & $0 / 24$ \\
Total & $13 / 19$ & $0 / 6$ & \\
\hline
\end{tabular}

Numerator indicates number of tissues in category in which E4 antigen was detected. Denominator indicates total number of tissues studied in that category. Each tissue was obtained from a different subject.

* Blots were probed under conditions of medium stringency and high stringency for HPV 6,11,16, 18, and 31 DNA.

${ }^{\ddagger}$ Squamous cell carcinoma.

of the E4 protein was found in all grades of CIN; it was detected primarily in the middle and superficial cell layers, and in many, but not all cells comprising these layers (Fig. $3 \mathrm{~A}$ ). In all grades of $\mathrm{CIN}$, the E4 protein was detected only in the epithelial cell nucleus.

When high and low grade CIN were present in the same tissue, E4 protein expression was generally more marked in areas containing the latter. However, expression did not correlate with cell differentiation per se, since the E4 protein was detected in lesions containing CIN 3, which exhibit little or no squamous differentiation. Instead, the location of the E4 protein within a lesion appeared to correlate with the location of HPV DNA as determined by in situ hybridization (Fig. 3, $B$ and $C$ ).

In addition to lesions containing $\mathrm{CIN}$, five invasive cancer tissues were obtained from subjects whose corresponding cervical swabs contained HPV 16 DNA. In these biopsies, the presence of HPV DNA was confirmed by in situ hybridization. However, in contrast to expression of the E4 protein in the superficial layers of CIN, the E4 protein was not detected in any of the cervical carcinoma tissues, even though these tissues contained HPV DNA. This finding was investigated further using the CaSki cell line, which contains HPV 16 DNA and was derived from a cervical cancer $(31,32)$. The E4 protein was not detected in this cell line with the HPV 16 E4 [20-34] antibodies by immunohistology (data not shown).

To determine the location of the E4 protein within the nuclei of HPV-infected cells, immunoelectron microscopy was performed on ultrathin cryosections of a cervical lesion using the E4 [20-34] antibodies. Approximately 120 cells per section from the superficial cell layers of the epithelium of a cervical lesion were screened. Arrays of spherical structures 25 to $35 \mathrm{~nm}$ in diameter were observed in the nuclei of 10 cells. These structures appeared to resemble partially assembled or partially degraded virions (Fig. 4, $A$ and $B$ ). The more compact arrays were labeled with gold particles, localizing the E4 protein to these structures (Fig. $4 \mathrm{~B}$ ). No colloidal gold particles were noted in other regions of the nucleus or in the cytoplasm, and no binding was noted in sections incubated with pre-immune IgG.

Detection of the $E 4$ protein in histologically normal tissue. It is now recognized that histologically normal cervical tissue can contain HPV DNA $(39,40)$. However, it is not known if any proteins specified by the viral genome are expressed in these tissues. This question was addressed by examining histologically normal tissues adjacent to the lesions described above. Of the 12 CIN tissues containing HPV 16 DNA, adjacent histologically normal tissue was present in 6 . In three of these six tissues, E4 protein expression was noted in areas that were otherwise normal histologically (Fig. $3 \mathrm{D}$ ), even though in situ hybridization studies of the same tissues revealed HPV DNA only in the lesional areas. This finding led to the examination of two tissues that were entirely normal histologically from patients whose cervical swabs contained HPV 16 DNA. E4 protein expression was noted in one of these two tissues. Although HPV 16 DNA could not be detected in this tissue by in situ hybridization, it was readily detected in a paraffin section of the same tissue using the polymerase chain reaction. In contrast, although hemoglobin DNA was successfully amplified from each of the samples, no HPV DNA was detected in three histologically normal, E4 protein-negative tissues from patients whose cervical swabs did not contain HPV DNA. Similarly, controls consisting of amplification of all components of the reaction except HPV DNA were negative for HPV amplification, and among the positive HPV DNA controls, there was no crossreactivity between primers and probes for each HPV type.

Specificity of antibodies to the HPV 16 E4 protein in cervical tissues. The results described above indicate that in cervical epithelia containing HPV 16 DNA, the E4 protein is expressed in some histologically normal tissues and in all grades of CIN, but not in cervical cancer. To investigate the possibility that the E4 [20-34] antibodies were actually recognizing a normal non-

Figure 3. $(A)$ E4 protein localization in a CIN 3 lesion. A cervical biopsy was obtained from a patient whose cervical swab contained HPV 16 DNA. The tissue was examined by immunohistochemistry for the presence of the E4 protein using $1.4 \mu \mathrm{g} / \mathrm{ml} \mathrm{of} \mathrm{the} \mathrm{affinity-purified} \mathrm{IgG}$ antibodies to the HPV 16 E4[20-34] peptide. Nuclei containing the E4 protein stain red (arrows) and are localized to the middle and superficial cell layers of the epithelium. Studies were also conducted with the same tissue using IgG obtained from the pre-immune serum and the non-peptide binding fraction of the immune serum; these antibodies did not bind the tissue (data not shown). Hematoxylin counterstain, paraffin-embedded, 4- $\mu$ m section, $\times 100$. (B) E4 protein localization in a CIN 1 lesion. A cervical biopsy was obtained from a patient whose cervical swab contained HPV 16 DNA. The tissue was examined for the presence of the E4 protein as described for the tissue shown in $A$. Hematoxylin counterstain, paraffin-embedded, 4- $\mu \mathrm{m}$ section, $\times 100$. $(C)$ Localization of HPV DNA by in situ hybridization in a CIN 1 lesion. The same tissue depicted in $B$ was studied using a biotin-labeled HPV 16/18 DNA probe. Nuclei containing HPV DNA stain blue (arrows). The distribution of the E4 protein $(B)$ and HPV DNA $(C)$ is similar. Nuclear Fast Red counterstain, paraffin-embedded, 4- $\mu$ m section, $\times 100$. $(D)$ E4 protein expression in a histologically normal tissue. A cervical biopsy was obtained from a patient whose cervical swab contained HPV 16 DNA. The tissue depicted in this figure is histologically normal, and is adjacent to a region that contains CIN 2 (not shown). Nuclei containing the E4 protein are apparent (arrows) in the superficial cell layers. Hematoxylin counterstain, paraffin-embedded, 4- $\mu \mathrm{m}$ section, $\times 100$. 


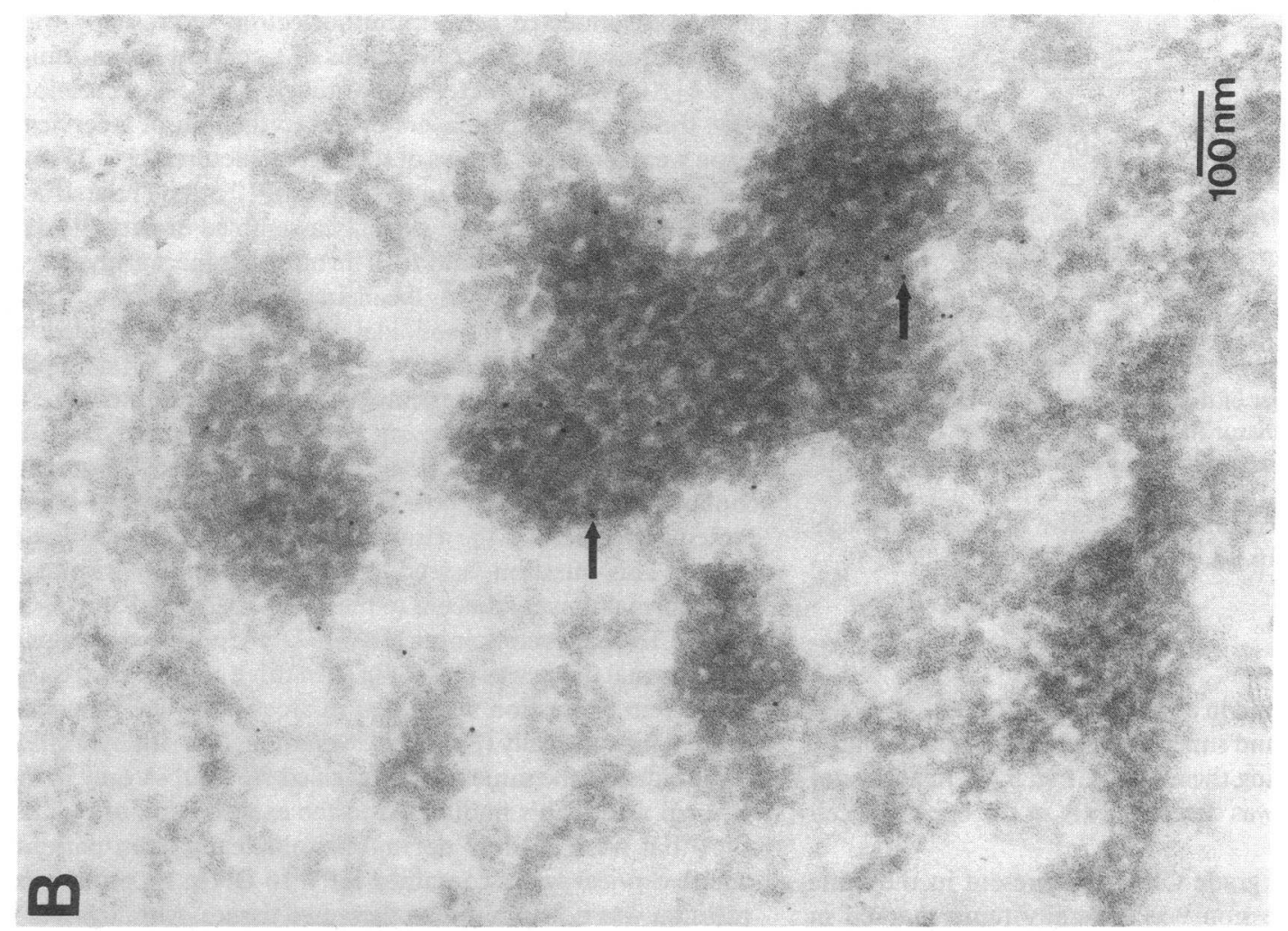

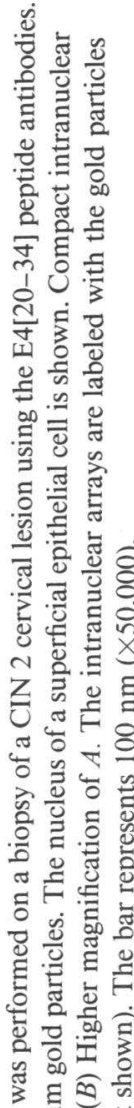

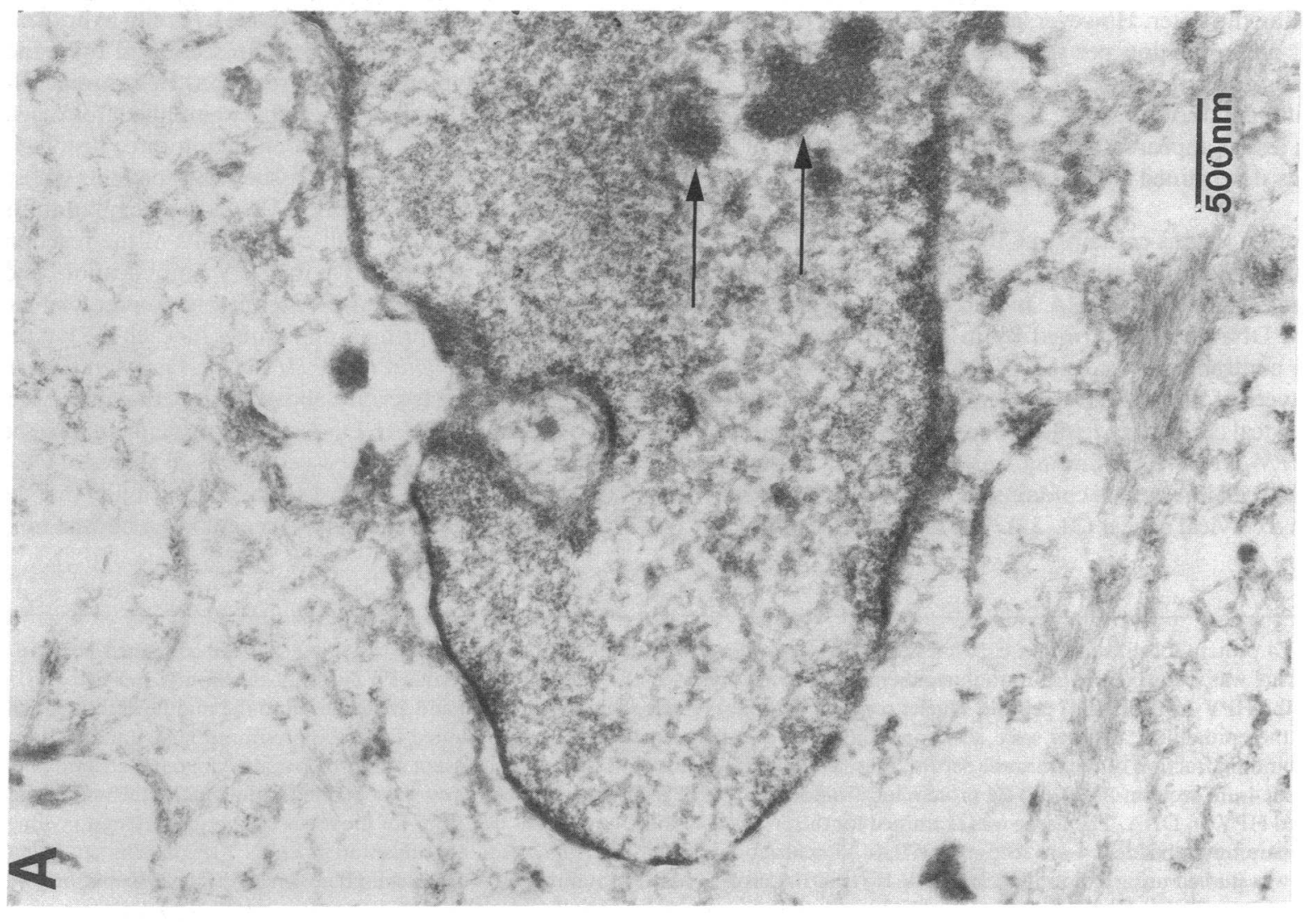

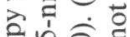

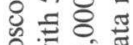

定

当 $\bar{x}$

政

造

8

要:

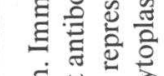

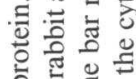

造通

斗吾要

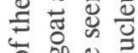

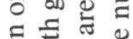

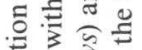

马े

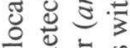

च

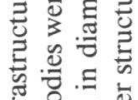

咅长

కิ저융

$\forall$ 吾它

密造产 
viral, crossreacting cellular antigen, or a cellular antigen induced by the abnormal histopathologic process giving rise to CIN, 24 tissues were obtained from subjects whose corresponding cervical swabs did not contain HPV types $6,11,16$, 18, or 31 DNA by Southern blotting. These tissues, which ranged from histologically normal to invasive cancer, were not bound by antibodies to the HPV 16 E4 peptide (Table I). An additional six tissues were obtained from subjects whose corresponding cervical swabs contained HPV 6/11 DNA, and none of these tissues were bound by the HPV 16 E4 antibodies. Consistent with their specificity for the HPV 16 E4 peptide demonstrated by RIA, this finding indicates that these antibodies react with tissues from subjects infected with HPV 16 DNA, but do not react with tissues from HPV-negative subjects or subjects infected with HPV 6 or 11 DNA, regardless of lesional status.

\section{Discussion}

Genital HPV infections are rapidly increasing in incidence (41) among both men and women, and the incidence of high grade CIN is increasing as well (42). In the United States, over 14,000 new cases of invasive SCC of the cervix are reported annually, resulting in $\sim 7,000$ deaths per year (43). In many developing countries, cancer of the cervix is a leading cause of death among young women (44). Thus, the prevalence of HPV as a sexually transmitted pathogen and its established connection to cancer underlie the need for a better understanding of HPV protein expression and the role of HPV proteins in the pathogenesis of cervical disease.

RNA in situ hybridization studies of HPV-infected cervical tissues have shown that transcripts from most of the early region ORFs can be detected in cervical biopsies (22). Of the early region transcripts, mRNA transcribed from the E4 ORF appears to be the most abundant in CIN tissues containing HPV 16 DNA. Similarly, mRNA from the E4 ORF was found to be the most abundant viral transcript in cervical condyloma acuminatum containing HPV 6 DNA (23). While the foregoing studies have documented the presence of HPV mRNAs in genital tissues, little is known about the corresponding proteins in these sites. Thus, in the present study, we have used E4 protein-specific antibodies to determine the presence and location of the E4 protein in HPV-infected cervical tissues, and the relationship between $\mathrm{E} 4$ protein expression and the severity of the associated histopathologic abnormalities.

Immunohistochemical studies with the affinity-purified antibodies to the HPV 16 E4[20-34] peptide indicated that they reacted with the HPV 16 sequence, but not with the corresponding sequence of HPV 6 or 11; this kind of HPV type-specificity was sought in this study in order to use this immunologic reagent to discriminate between HPV 16 and HPV 6- or 11 -infected cells. We further sought to determine if the antibodies that had been elicited to the HPV 16 E4[20-34] peptide could bind the corresponding region of the full-length HPV 16 E4 protein. As indicated in Fig. $2 b$, the reactivity of the antibodies to the HPV 16 E4[20-34] peptide was approximately four times greater than for the full-length protein. This kind of diminished reactivity of an anti-peptide antibody for the corresponding full-length native protein is a well-documented phenomenon (45) and appears to be due to: $(a)$ antibodies to the free amino and carboxy terminus of the small peptide that do not crossreact with the same sequence when present as an internal region of a longer protein; and $(b)$ possible differences in the higher order structure of an epitope within a peptide versus the same epitope when present as part of a folded protein. Thus, while these antibodies bound the E4[20-34] peptide better than the full-length E4 protein, they nonetheless bound the longer protein specifically and in relatively high titer.

Using these antibodies, E4 protein expression was localized to cells comprising the middle and superficial cell layers of the cervical squamous epithelium (Fig. 3). Previous studies have shown that E4 mRNA in CIN containing HPV 16 DNA is also found in the same epithelial cell strata (22). Similarly, late region protein expression occurs in the upper cell layers of the epithelium (14). One interpretation of these findings is that HPV gene expression is linked to cell differentiation, since the middle and superficial layers of the epithelium contain cells that are more differentiated than cells comprising the basal layer. However, DNA in situ hybridization studies of both high and low grade lesions (e.g., Fig. $3 C$ ) show that most of the cells harboring substantial quantities of HPV DNA are also located in the middle and superficial cell layers, indicating that these strata contain the highest DNA copy number. Thus, a second interpretation of the localization data is that expression of the E4 protein in the superficial layers of these tissues may simply be due to an increased viral DNA copy number in the cells comprising these layers. This in turn may be associated with a higher level of E4 mRNA and protein expression in these cells. This explanation is supported by the observation that E4 protein expression is also evident in the middle and superficial cell layers of CIN 3 lesions harboring HPV 16 DNA (Fig. $3 A$ ), even though these lesions are principally composed of immature, poorly differentiated cells.

The E4 protein was not found in any of five invasive cervical cancer tissues containing HPV 16 DNA, indicating that it may not be expressed at this stage of disease. Similarly, it was not detected in the CaSki cell line (data not shown). Loss of E4 protein expression in these tissues and cells could be due to alteration or diminution of E4 transcription after malignant transformation. Evidence in support of this possibility comes from studies of cervical cancer cell lines containing either HPV 16 or 18 DNA, in which the major detectable viral transcripts are specified by ORFs other than E4 $(46,47)$. Furthermore, studies of cervical cancer tissues containing HPV 16 DNA have shown that integration of the viral genome into the host chromosome may occur at this stage of the disease (48); this integration event might result in the disruption or deletion of the E4 ORF. Alternatively, decreased E4 protein expression in cancer cells could be due to a post-transcriptional block, as suggested by studies in CaSki cells. In these studies, the E4 protein was detectable among the in vitro translation products of CaSki cell mRNA, but was not detected in protein extracts of these cells using immunoprecipitation of $\left[{ }^{35} \mathrm{~S}\right]$ methionine-labeled cells (46). Additional studies will be required to determine whether loss of E4 protein expression is causally related to the oncogenic process or is simply an associated finding.

In addition to its expression in CIN lesions, E4 protein expression can be detected in some histologically normal tissues containing HPV 16 DNA, whether these tissues are adjacent to lesional areas or are completely normal histologically (Table I). This finding was unexpected, since HPV DNA and mRNA have rarely been found in such tissues by in situ hybridization. However, by analyzing a larger number of cells using the Southern blot hybridization technique, HPV DNA could be detected in histologically normal tissue located up to $5 \mathrm{~cm}$ from 
lesions shown to contain HPV DNA $(39,40)$. Thus, not only can histologically normal tissues contain HPV DNA, but the viral genome in such tissues can direct the synthesis of the E4 protein. Accumulation of the $\mathrm{E} 4$ protein in such tissues may therefore precede the development of histologic abnormalities, although we cannot rule out the possibility that we are detecting E4 expression in what was recently lesional tissue that had regressed to histologic normalcy.

Our immunohistochemical and immunoelectron microscopy studies localize E4 protein expression to the cell nuclei of HPV-infected tissues. In contrast, Doorbar et al. detected large quantities of E4 protein in the cytoplasm of plantar warts infected by HPV 1a; they also found that the E4 ORF of this HPV type can encode a family of polypeptides differing in size, posttranslational modifications, and possibly, functions (21). Breitburd et al. detected the E4 protein in both cytoplasmic and nuclear inclusions of HPV 1-infected warts, and observed that cell keratinization was disturbed in cells containing the $\mathrm{E} 4$ protein (49). However, HPV 1a, in contrast to HPV 16, is not believed to be a sexually transmitted pathogen and causes only benign lesions of the skin. Thus, localization of the HPV 16 E4 protein exclusively to the cell nucleus using the antibodies described in this report may be due to intrinsic differences in the biology of these two HPV types. Alternatively, other HPV 16 E4 protein variants could be present in the cytoplasm and these might lack the epitope recognized by antibodies to the HPV 16 E4[20-34] peptide. Evidence for this includes the observation of $E 4$ protein expression in the cytoplasm of a small number of CIN biopsies positive for HPV 16 or 18 DNA using antibodies to a segment of the E4 protein expressed in Escherichia coli (50). It is also possible that the concentration of the $\mathrm{E} 4$ protein in the cytoplasm of these cells is too low to be detected by our assay.

The significance of $\mathrm{E} 4$ protein expression for the pathobiology of CIN and invasive cancer is not yet known. Studies with bovine papillomavirus indicate that mutation of its E4 ORF does not alter the transforming ability of the virus (51). Because viral capsid proteins are present in the cell nucleus, the nuclear location of the $\mathrm{E} 4$ protein may be consistent with a role in the process of virus maturation or as a structural protein. If so, it would be functionally analogous to a "late region" protein as suggested by Doorbar et al. (21). Our ultrastructural studies are consistent with this hypothesis; within the nucleus, the E4 protein appears to be organized into regular arrays that have the appearance of viral particles, but with a diameter less than that of an intact viral capsid, which is $\sim 55 \mathrm{~nm}$ (52). Of note, however, L1 and L2 gene expression are not necessarily linked to E4 expression, because in contrast to our finding that E4 expression often occurs in high grade CIN, most cases of high grade CIN are not found to contain the $\mathrm{L} 1$ and $\mathrm{L} 2$ proteins (14). Further studies will be needed, however, to determine the significance of these findings for the function of the E4 protein, the significance of its loss of expression in cervical cancer, and the prognostic implications of the detection of the protein in normal tissues.

\section{Acknowledgments}

We thank Jennifer Kidd, B.S., Norman Arnheim, Ph.D., Darryl Shibata, M.D., Dorothy Bainton, M.D. and the Colposcopy Clinic nurses and residents of S.U.H., S.F.G.H., and U.C.S.F., for their assistance and support.
This work was supported by Life Technologies, Inc., National Cancer Institute grant CA-43871, and by the Cancer Research Coordinating Committee of the University of California. J. M. Palefsky was a fellow of the Medical Research Council of Canada and the American Social Health Association.

\section{References}

1. Gissmann, L. 1984. Papillomaviruses and their association with cancer in animals and in man. Cancer Surv. 3:161-181.

2. Boshart, M., L. Gissmann, H. Ikenberg, A. Kleinheinz, W. Scheurlen, and H. zur Hausen. 1984. A new type of papillomavirus DNA, its presence in genital cancer biopsies and in cell lines derived from cervical cancer. EMBO (Eur. Mol. Biol. Organ.) J. 3:1151-1157.

3. Gissman, L., M. Boshart, M. Durst, H. Ikenberg, D. Wagner, and H. zur Hausen. 1984. Presence of human papillomavirus in genital tumors. J. Invest. Dermatol. 83:26s-28s.

4. Champion, M. J., D. J. McCance, J. Cuzick, and A. Singer. 1986. Progressive potential of mild cervical atypia: Prospective cytologic, colposcopic, and virologic study. Lancet. ii:236-240.

5. Nash, J. D., T. W. Burke, and W. J. Hoskins. 1987. Biologic course of cervical human papillomavirus infection. Obstet. Gynecol. 69:160-162.

6. Gissmann, L. 1984. Papillomaviruses and their association with cancer in animals and in man. Cancer Surv. 3:161-181.

7. Reid, R., M. Greenberg, A. B. Jenson, M. Husain, J. Willett, Y. Daoud, G Temple, C. R. Stanhope, A. L. Sherman, and G. D. Phibbs. 1987. Sexually transmitted papillomaviral infections. I. The anatomic distribution and pathologic grade of neoplastic lesions associated with different viral types. Am.J. Obstet. Gynecol. 156:212-222.

8. Crum, C., M. Mitao, R. Levine, and S. Silverstein. 1985. Cervical papillomaviruses segregate within morphologically distinct precancerous lesions. $J$. Virol. 54:675-681.

9. Beaudenon, S., D. Kremsdorf, O. Croissant, S. Jablonska, S. Wain-Hobson, and G. Orth. 1986. A novel type of human papillomavirus associated with genital neoplasias. Nature (Lond.). 321:246-249.

10. Lorincz, A. T., A. Quinn, W. Lancaster, and G. F. Temple. 1987. A new type of papillomavirus associated with cancer of the uterine cervix. Virology. 159:187-190.

11. Lorincz, A. T., W. Lancaster, and G. Temple. 1986. Cloning and characterization of a new human papillomavirus from a woman with dysplasia of the uterine cervix. $J$. Virol. 58:225-229.

12. Fuchs, P. G., F. Girardi, and H. Pfister. 1988. Human papillomavirus DNA in normal, metaplastic, preneoplastic and neoplastic epithelia of the cervix uteri. Int. J. Cancer. 41:41-45.

13. Seedorf, K., G. Krammer, M. Durst, S. Suhai, and W. Rowekamp. 1985. Human papillomavirus type 16 DNA sequence. Virology. 145:181-185.

14. Firzlaff, J. M., N. B. Kiviat, A. M. Beckmann, S. A. Jenison, and D. A Galloway. 1988. Detection of human papillomavirus capsid antigens in various squamous epithelial lesions using antibodies directed against the L1 and L2 open reading frames. Virology. 164:467-77.

15. Lusky, M., and M. R. Botchan. 1985. Genetic analysis of bovine papillomavirus type 1 trans-activating replication factors. J. Virol. 53:955-965.

16. Lambert, P., and P. M. Howley. 1988. Bovine papillomavirus type E replication-defective mutations are altered in their transcriptional regulation. $J$. Virol. 62:4009-4015.

17. Moskaluk, C., and D. Bastia. 1987. The E2 "gene" of bovine papillomavirus encodes an enhancer binding protein. Proc. Natl. Acad. Sci. USA. 84:1215 1218.

18. Phelps, W. C., C. L. Yee, K. Munger, and P. M. Howley. 1988. The human papillomavirus type $16 \mathrm{E} 7$ gene encodes trans-activation and transformation functions similar to those of adenovirus E1a. Cell. 53:539-547.

19. Storey, A., D. Pim, A. Murray, K. Osborn, L. Banks, and L. Crawford 1988. Comparison of the in vitro transforming activities of the human papillomavirus types. EMBO (Eur. Mol. Biol. Organ.) J. 7:1815-1820.

20. Neary, K., and D. Dimaio. 1989. Open reading frames E6 and E7 of bovine papillomavirus type 1 are both required for full transformation of mouse C127 cells. J. Virol. 63:259-266.

21. Doorbar, J., D. Campbell, R. J. A. Grand, and P. H. Gallimore. 1986 Identification of the human papilloma virus-1a E4 gene products. $E M B O$ (Eur. Mol. Biol. Organ.) J. 5:355-362.

22. Crum, C. P., G. Nuovo, D. Friedman, and S. J. Silverstein. 1988. Accumulation of RNA homologous to human papillomavirus type 16 open reading frames in genital precancers. J. Virol. 62:84-90.

23. Stoler, M. H., S. M. Wolinsky, A. Whitbeck, T. R. Broker, and L. T. Chow. 1989. Differentiation-linked human papillomavirus types 6 and 11 transcription in genital condylomata revealed by in situ hybridization with messagespecific RNA probes. Virology. 172:331-340.

24. Ferenczy, A., and B. Winkler. 1987. Cervical intraepithelial neoplasia and 
condyloma. In Blaustein's Pathology of the Female Genital Tract. Third Edition. R. Kurman, editor. Springer-Verlag New York, Inc., New York. 177-217. 25. Stewart, J. M., and J. D. Young. 1969. In Solid Phase Peptide Synthesis. Freeman Publications, San Francisco. 1-103.

26. Schmidt, A., P. O’Hanley, and G. Schoolnik. 1984. Gal-Gal pyelonephritis Escherichia coli pili linear immunogenic and antigenic epitopes. J. Exp. Med. 161:707-717.

27. Chow, L. T., M. Nasseri, S. M. Wolinsky, and T. R. Broker. 1987. Human papillomavirus types 6 and $11 \mathrm{mRNAs}$ from genital condylomata acuminata. $J$. Virol. 61:2581-2588.

28. Atherton, E., and R. C. Sheppard. 1985. Solid phase peptide synthesis using $N$-alpha-fluorenylmethoxylcarbonyl amino acids pentafluorophenyl esters. J. Chem. Soc. Chem. Commun. 3:165-166.

29. Laemmli, U. K. 1970. Cleavage of structural protein during the assembly of the head of bacteriophage T4. Nature (Lond.). 227:680-685.

30. Towbin, H., T. Staehelin, and J. Gordon. 1979. Electrophoretic transfer of proteins from polyacrylamide gels to nitrocellulose sheets: procedure and some applications. Proc. Natl. Acad. Sci. USA. 76:4350-4354.

31. Hsu, S. M., and L. Raine. 1984. The use of avidin-biotin-peroxidase complex $(\mathrm{ABC})$ in diagnostic and research pathology. In Advances in Immunohistochemistry. R. A. DeLellis, editor. Masson Publishing USA, New York. 3142.

32. Gelderblom, H., C. Kocks, J. L'age-Stehr, and H. Reupke. 1985. Comparative immunoelectron microscopy with monoclonal antibodies on yellow fever virus-infected cells: pre-embedding labelling versus immunocryoultamicrotomy. J. Virol. Methods. 10:225-239.

33. Griffiths, G., A. McDowall, R. Back, and J. Dubochet. 1984. On the preparation of cryosections for immunocytochemistry. J. Ultrastruct. Res. 89:65-78.

34. Southern, E. M. 1975. Detection of specific sequences among DNA fragments separated by gel electrophoresis. J. Mol. Biol. 98:503-517.

35. Shibata, D., N. Arnheim, and W. J. Martin. 1988. Detection of human papilloma virus in paraffin-embedded tissue using the polymerase chain reaction. J. Exp. Med. 167:225-230.

36. Hopp, T., and K. Woods. 1981. Prediction of protein antigenic determinants from amino acid sequences. Proc. Natl. Acad. Sci. USA. 78:3824-3828.

37. Levitt, M. 1976. A simplified representation of protein conformations for rapid simulation of protein folding. J. Mol. Biol. 104:59-107.

38. Chou, P., and G. Fasman. 1974. Conformational parameters for amino acids in helical b-sheet, and random coils calculated from proteins. Biochemistry. 13:211-245.

39. Ferenczy, A., M. Mitao, N. Nagai, S. Silverstein, and C. Crum. 1985. Latent papillomavirus and recurring genital warts. N. Engl. J. Med. 313:784-788.
40. McNab, J. C. M., S. A. Walkinshaw, J. W. Cordiner, and J. B. Clements. 1986. Human papillomavirus in clinically and histologically normal tissue of patients with genital cancer. N. Engl. J. Med. 315:1052-1058.

41. Centers for Disease Control. 1983. Condyloma acuminatum in the United States, 1966-1981. Mortality Morbidity Weekly Rep. 32:306-308.

42. Sadeghi, S. B., E. W. Hsieh, and S. W. Gunn. 1984. Prevalence of cervica intraepithelial neoplasia in sexually active teenagers and young adults. $\mathrm{Am}$. J. Obstet. Gynecol. 148:726-729.

43. Silverberg, E., and J. Lubera. Cancer statistics, 1986. CA-Cancer J. Clin. 36:9-25.

44. Rosenburt, M., K. Schulz, and N. Burton. 1986. Sexually transmitted diseases in sub-Saharan Africa. Lancet. ii: 152.

45. Judd, A. K., and G. K. Schoolnik. 1990. Peptides: chemistry, biology and pharmacology. Adv. Pharmacol. 21:221-285.

46. Seedorf, K., T. Oltersdorf, G. Krammer, and W. Rowekamp. 1987. Identification of early proteins of the human papilloma virus type 16 (HPV 16) and type 18 (HPV 18) in cervical carcinoma cells. EMBO (Eur. Mol. Biol. Organ.) J. 6:139-144.

47. Smotkin, D., and F. Wettstein. 1986. Transcription of human papillomavirus type 16 early genes in a cervical cancer and a cancer-derived cell line and identification of the E7 protein. Proc. Natl. Acad. Sci. USA. 83:4680-4684.

48. Durst, M., C. M. Croce, L. Gissmann, E. Schwarz, and K. Huebner. 1987. Papillomavirus sequences integrate near cellular oncogenes in cervical carcinomas. Proc. Natl. Acad. Sci. USA. 84:1070-1074.

49. Breitburd, $F$, O. Croissant, and G. Orth. 1987. Expression of human papillomavirus type-1 E4 gene products in warts. Cancer Cells. 5:115-122.

50. Crum, C. P., S. Barber, M. Symbula, K. Snyder, A. M. Saleh, and J. K. Roche. 1990. Coexpression of the human papillomavirus type 16 E4 and L1 open reading frames in early cervical neoplasia. Virology. 178:238-246.

51. Neary, K., B. Horwitz, and D. DiMiao. 1987. Mutational analysis of open reading frame E4 of bovine papillomavirus type 1. J. Virol. 61:1248-1252.

52. Fraenkel-Conrat, H., and P. C. Kimball. 1982. Small genome DNA viruses. In Virology. H. Fraenkel-Conrat and P. C. Kimball, editors. Prentice-Hall, Inc., Englewood Cliffs, NJ. 159-198.

53. Schwar, E., M. Durst, C. Demankowski, O. Lattermann, R. Zeck, E. Wolfsperger, S. Suhai, and H. zur Hausen. 1983. DNA sequence and genome organization of genital human papillomavirus type 6b. EMBO (Eur. Mol. Biol. Organ.) J. 2:2341-2348.

54. Dartmann, K., E. Schwarz, L. Gissmann, and H. zur Hausen. 1986. The nucleotide sequence and genome organization of human papillomavirus type 11 . Virology. 151:124-130. 